\title{
EXACERBATIONS OF CHRONIC OBSTRUCTIVE PULMONARY DISEASE AND IMPLEMENTATION OF GUIDELINES GOLD 2011 IN PRACTICE
}

\author{
${ }^{1}$ Osinová D, ${ }^{2}$ Sadloňová J, ${ }^{3}$ Rozborilová E. \\ ${ }^{1}$ Department of Anesthesiology and Intensive Care, Jessenius Faculty of Medicine, Commenius University and \\ University Hospital in Martin, Slovakia \\ ${ }^{2}$ First Department of Internal Medicine, Jessenius Faculty of Medicine, Commenius University and University \\ Hospital in Martin, Slovakia \\ ${ }^{3}$ Department of Pneumology and Phtiseology, Jessenius Faculty of Medicine, Commenius University and \\ University Hospital in Martin, Slovakia
}

\begin{abstract}
A bstract
Background: Chronic obstructive pulmonary disease (COPD) is a disease that is characterized by a persistent blockage of airflow from the lungs. It is an under-diagnosed, life-threatening disease which is not fully reversible. COPD is not only global health problem, the disease is also serious economic problem.

Objective: The aim of this study was to evaluate the effects of implementation of new guidelines Global Initiative for Chronic Obstructive Lung Disease (GOLD) for diagnosis and treatment of chronic obstructive pulmonary disease (COPD).

Design: Consecutive, observational, retrospective, mono-centric study.

Methods: Into the study were included all patients admitted with COPD exacerbations to Department of Pneumology and Phtiseology, Jessenius Faculty of Medicine in Martin and University Hospital, separately in year 2008 and year 2013, who have satisfied the inclusion criteria. Those years were chosen specifically from the reason of biennial application of diagnosis and treatment, according to recommended guidelines GOLD 2006 and GOLD 2011 , in practice. The study was focused on the basic anthropometric parameters, data of medical history, complications of underlying disease, comorbidities, laboratory parameters, treatment strategy of patients after release from hospital and mortality within one year were evaluated.

Results: Patients in group 2013, when were applied guidelines GOLD 2011 had a higher average oxygen saturation and higher $\mathrm{pO}_{2}$ at all stages of the disease, significantly in GOLD D. They had higher values of FEV and FVC significantly in GOLD B. There was decrease of overuse of inhalation corticosteroids in group GOLD B from $53.34 \%$ to $28.57 \%$. There was a downturn in use of theophylline, significantly in GOLD C. The average number of exacerbations leading to hospitalizations was lower in group 2013 in all stages of the disease. One-year mortality of patients in group 2013 was lower.

Conclusions: The implementation and application of guidelines GOLD 2011 in practice is a challenging and complex process, which is in region of University hospital Martin gradually and successfully implemented. The achievement the objectives of the GOLD 2011 not only contributes to the efficiency of prevention and timely diagnosis, but mainly on setting of adequate treatment, improves survival and quality of life of patients with COPD.
\end{abstract}

Keywords: Chronic obstructive pulmonary disease (COPD), exacerbation, co-morbidities, guidelines GOLD

\section{INTRODUCTION}

The chronic obstructive pulmonary disease (COPD) is a disease that affects approximately $10 \%$ of the world population in age over 40 years (1). It is expected, that by the year 2020, COPD will be the third leading cause of death in the world. In addition the COPD is not only global health problem, the disease is also serious economic problem. In the European Union the total direct health care costs of COPD patients are around 39 billion per year (2).

Global Initiative for Chronic Obstructive Lung Disease (GOLD) issued in 2011 the most comprehensive revision of previously existing guidelines for diagnosis and treatment of COPD. These recommendations were further in 2013, 2014 and 2015 revised again and partially modified $(3,4,5)$. Design of new guidelines, understands the patient as individuality and for the decision-making process is decisive to consider the patient as an

Address for correspondence:

Department of Anesthesiology and Intensive Care, Jessenius Faculty of Medicine, Commenius University and University Hospital in Martin, Mala hora Str. N. 4A, 03601 Martin, Slovakia; e-mail: denisa.osinova@gmail.com 
individual, for which are the interventions adapted. The expected effect should be better cooperation of patients, earlier detection of the disease, reducing the number of exacerbations, improving the quality of patient $s$ life and reduce mortality. The aim of our study was to evaluate the implementation of the guidelines for diagnosis and treatment of COPD according to the GOLD classification in practice. As part of the study design effects have been set more goals to systematically evaluate the individual steps recommended procedures and their effect on the studied parameters.

\section{METHODS}

The study has the design of consecutive, observational, retrospective, single-center study. Into the research were selected hospitalized patients with COPD exacerbations, in years 2008 and 2013. The both groups of patients were studied retrospectively. Diagnosis and treatment of the disease was in accordance with the recommended guidelines GOLD 2006 and GOLD 2011 which were valid for both groups 2 years. Into the research were included all patients hospitalized with COPD exacerbations on Department of Pneumology and Phtiseology University Hospital in Martin and have accomplished the inclusion criteria.

The inclusion criteria for patient selection to each group were: hospitalization in a given year for exacerbation of COPD, spirometry fulfilled the criteria for COPD, complete and accessible documentation during hospitalization with available data about appropriate tests and treatment.

Monitored parameters were: basic anthropometric data (age, height, weight, gender, BMI), anamnestic data (an allergic history, smoking history), complications of the disease resulting from the pathophysiologic mechanisms (hyperinflation, pulmonary hypertension, emphysema, cor pulmonale), co-morbidities, laboratory parameters (blood count, blood gases, CRP, the value of spirometry examination), the treatment strategy after discharge from hospital and mortality within one year.

All the parameters were compared between the two groups, and for each stage of the disease. We compared the stages of disease GOLD 2 and GOLD B, the GOLD 3 and GOLD C, GOLD 4 and GOLD D. Due to a zero numbers of patients in the group GOLD A, the group GOLD 1 was excluded from the comparison. Due to greater transparency, were the roman numerals in the disease stages 2008 replaced by the arabic numerals.

The results were processed, analyzed and statistically evaluated in Microsoft Excel. The data were statistically evaluated by comparison of quartiles, by analysis of variance (ANOVA) and by chi-square test. The differences were considered as significant in the level of statistical significance $\mathrm{p}<0.05$.

\section{RESULTS}

The research included a total of 84 patients, of which 63 were men and 21 women. To the group from year 2008 were included 35 patients and the percentage of disease stages in the group of 2008 was: GOLD 1 - 5\%, GOLD 2 - 46\%, GOLD $3-23 \%$ and GOLD $4-26 \%$.

To the group from year 2013 were included 49 patients and the percentage of disease stages in this group was: GOLD A - 0\%, GOLD B - 14\%, GOLD C - 33\% and GOLD D - 53\%.

The average age in group 2008 for each stage of the disease was in GOLD $2-74.88$ years $(\mathrm{SD} \pm 1.04)$, in GOLD 3 - 66.13 years (SD \pm 6.05$)$, GOLD $4-71.88$ years (SD \pm 9.13 ).

In a group of 2013, the average age in years for the different stages of the disease was in group GOLD B -68.42 years (SD \pm 12.56$)$, in group GOLD C -69.86 years (SD \pm 10.19 ) and in group GOLD D - 68.57 years (SD \pm 9.29 ).

In the group 2008 had a positive smoking history $54.42 \%$ of the patients and from this group $27.78 \%$ of patients were smokers despite diagnosed COPD. In the group of 2013 had 
a positive smoking history $63.26 \%$ of the patients and from this group $51.61 \%$ of patients were smokers despite diagnosed COPD.

\section{Arterial blood gases (ASTRUP)}

Among laboratory parameters were monitored results of the examination arterial blood gases - oxygen saturation $\left(\mathrm{SpO}_{2}\right)$, partial pressure of oxygen $\left(\mathrm{pO}_{2}\right)$ and partial pressure of carbon dioxide $\left(\mathrm{pCO}_{2}\right)$.

The average values and $\mathrm{SD}$ of oxygen saturation, partial pressure of oxygen $\left(\mathrm{pO}_{2}\right)$ and partial pressure of carbon dioxide $\left(\mathrm{pCO}_{2}\right)$ depending on stages of disease are in table 1 . Symbol $(*)$ shows the level of statistical significance $\mathrm{p}<0.05$.

In all stages of the disease, patients in group 2013 were found higher mean value of oxygen saturation $\left(\mathrm{SpO}_{2}\right)$, partial pressure of oxygen $\left(\mathrm{pO}_{2}\right)$ in arterial blood and lower average values of the partial pressure of carbon dioxide $\left(\mathrm{pCO}_{2}\right)$. Significantly higher values of $\mathrm{pO}_{2}$ in arterial blood we found only in group GOLD D. In comparison the average values of hypoxemia and hypercapnia were in group 2013 more favorably than in group 2008.

Table 1. The comparison of average values $\pm \mathrm{SD}$ of $\mathrm{SpO}_{2}, \mathrm{pO}_{2}$ and $\mathrm{pCO}_{2}$ in groups 2008 and 2013 depend on stage of diseases.

\begin{tabular}{|c|c|c|c|c|c|c|}
\hline \multirow{2}{*}{$\begin{array}{c}\text { Stages of } \\
\text { disease }\end{array}$} & \multicolumn{2}{|c|}{ Group 2008} & \multirow{2}{*}{$\begin{array}{c}\text { Stages of } \\
\text { disease }\end{array}$} & \multicolumn{2}{|c|}{ Group 2013} & \multirow[b]{2}{*}{$\mathrm{p}$} \\
\hline & $\mathrm{SpO}_{2}$ & SD & & $\mathrm{SpO}_{2}$ & $\mathrm{SD}$ & \\
\hline GOLD 2 & 86.43 & \pm 9.80 & GOLD B & 94.07 & \pm 2.57 & 0.0594 \\
\hline GOLD 3 & 84.14 & \pm 9.60 & GOLD C & 91.95 & \pm 3.17 & 0.1741 \\
\hline GOLD 4 & 84.66 & \pm 8.78 & GOLD D & 90.70 & \pm 4.64 & 0.0633 \\
\hline- & pO2 & $\mathrm{SD}$ & - & pO2 & $\mathrm{SD}$ & - \\
\hline GOLD 2 & 7.41 & \pm 2.09 & GOLD B & 9.00 & \pm 0.79 & 0.0672 \\
\hline GOLD 3 & 7.37 & \pm 2.00 & GOLD C & 8.56 & \pm 1.52 & 0.1312 \\
\hline GOLD 4 & 6.26 & \pm 1.85 & GOLD D & $8.26^{*}$ & \pm 1.40 & *0.0026 \\
\hline - & $\mathrm{pCO} 2$ & $\mathrm{SD}$ & - & $\mathrm{pCO} 2$ & $\mathrm{SD}$ & - \\
\hline GOLD 2 & 5.23 & \pm 1.14 & GOLD B & 4.67 & \pm 0.67 & 0.6048 \\
\hline GOLD 3 & 5.59 & \pm 1.77 & GOLD C & 5.05 & \pm 0.96 & 0.3494 \\
\hline GOLD 4 & 7.09 & \pm 1.98 & GOLD D & 5.89 & \pm 1.44 & 0.0693 \\
\hline
\end{tabular}

\section{Spirometry}

Diagnosis of COPD is based on the confirmation of airway obstruction, which is not fully reversible. Spirometry is a fundamental indicator needed to determine the stage and progression of the disease. The results of spirometry measurements of forced vital capacity (FVC) and forced expiratory volume in 1 second $\left(\mathrm{FEV}_{1}\right)$ in group 2008 and 2013 at different stages of the disease are shown by the median and interquartile scattering in Figures 1 and 2. Significant difference $(\mathrm{p}<0.05)$ in parameters of spirometry FVC and FEV1 was observed in patients between groups GOLD 2 and GOLD B. 


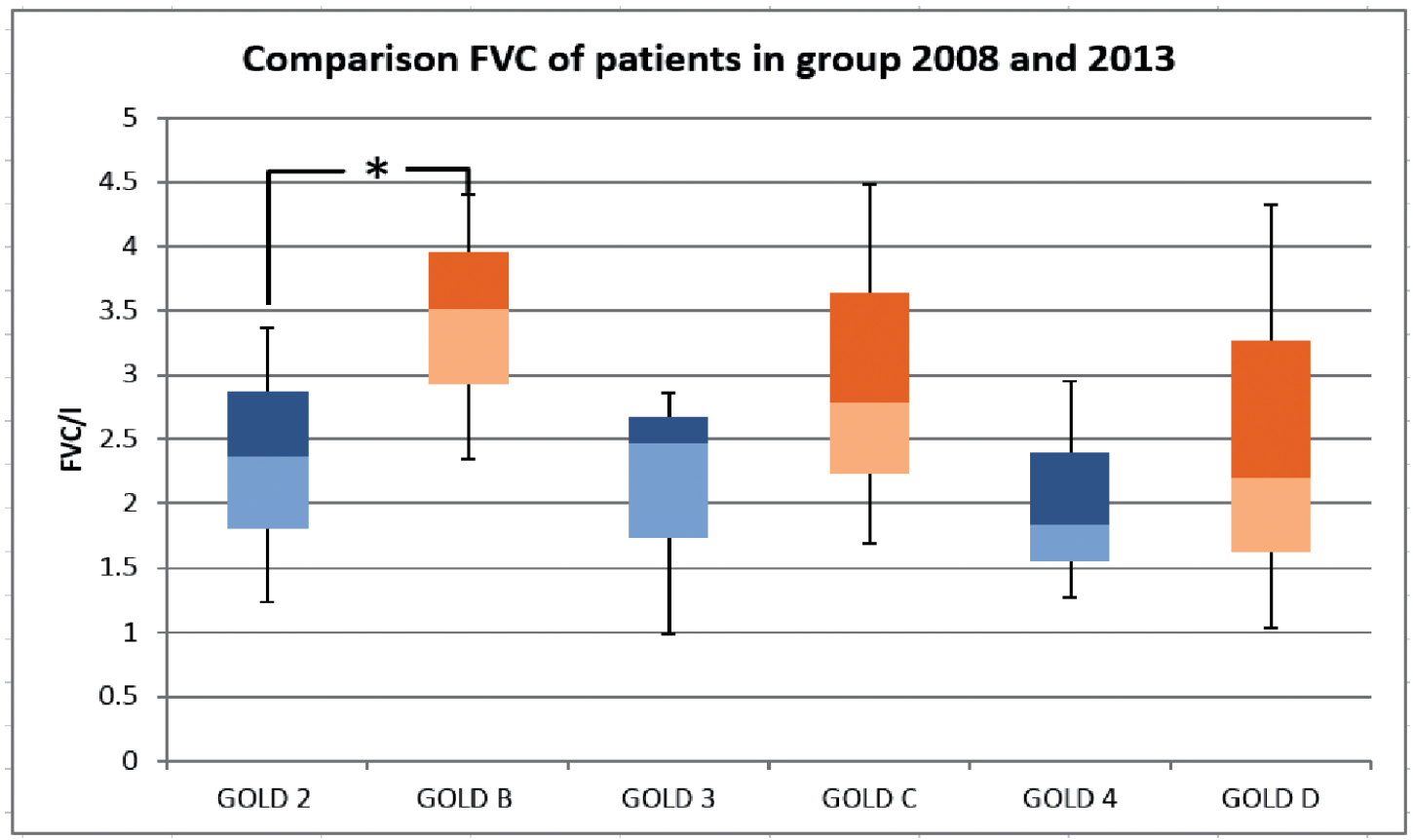

Fig 1. Comparison result of FVC patients in group 2008 (GOLD 2, 3, 4) and 2013 (GOLD B, C, D) in relation to the stage of the disease. * Significant differences $\mathrm{p}<0.05$

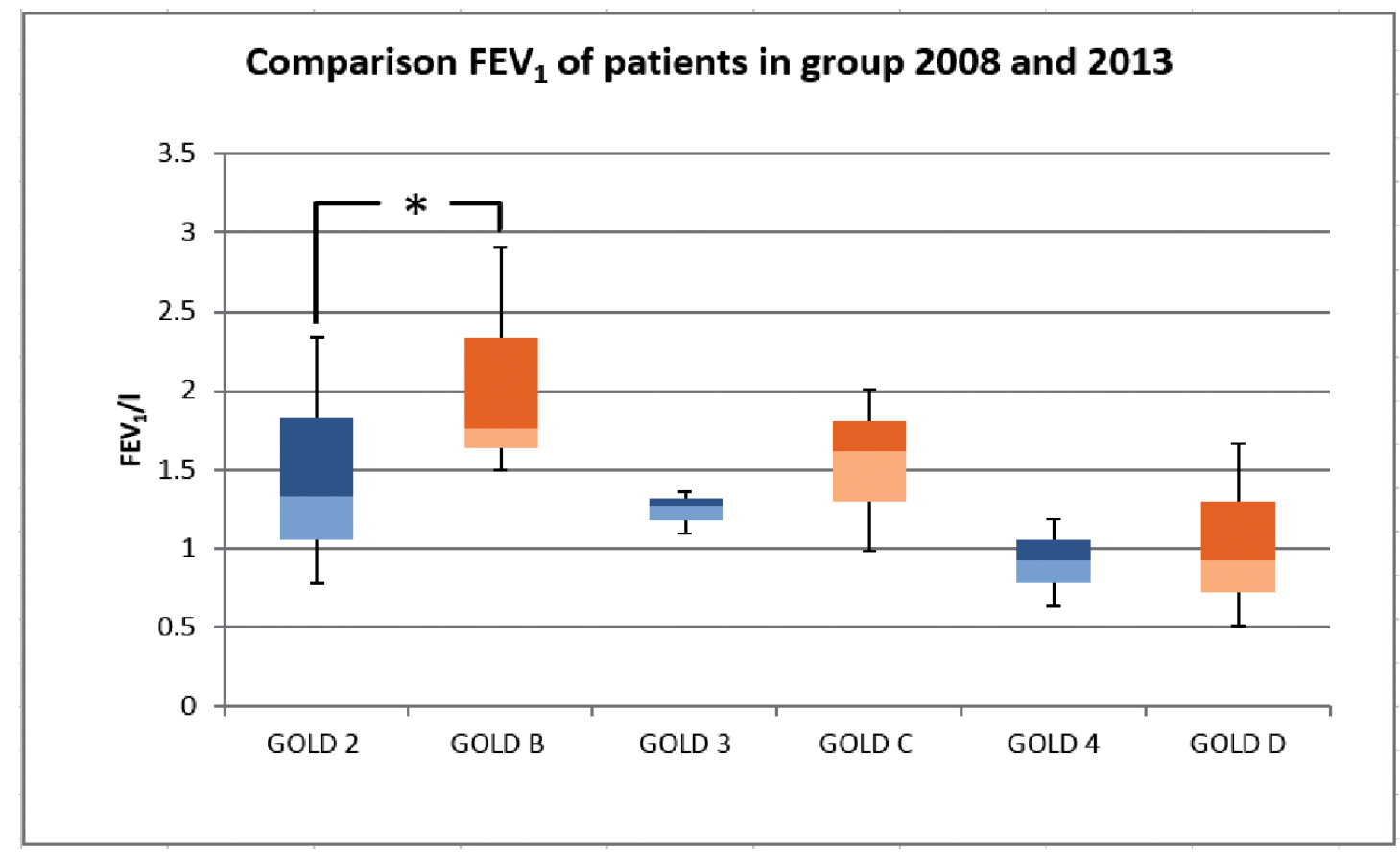

Fig 2. Comparison result of $\mathrm{FEV}_{1}$ patients in group 2008 (GOLD 2, 3, 4) and 2013 (GOLD B, C, D) in relation to the stage of the disease. * Significant differences $\mathrm{p}<0.05$ 


\section{Treatment strategy}

In the groups 2008 and 2013 were studied and compared different treatment strategies according to the stage of the disease. The active substances and their combinations used in dependence on stage of disease GOLD were monitored. Table 2 shows the percentage of the recommended use of the compared groups of drugs in various stages of the disease.

Table 2. The comparison of the treatment strategy of patients in different stages of the disease, the percentage expressing the number of patients prescribed active ingredient.

* Significant differences $\mathrm{p}<0.05$; Substances and their combinations.

\begin{tabular}{|l|c|c|c|c|c|c|}
\hline & $\begin{array}{c}\text { GOLD 2 } \\
\%\end{array}$ & $\begin{array}{c}\text { GOLD B } \\
\%\end{array}$ & $\begin{array}{c}\text { GOLD 3 } \\
\%\end{array}$ & $\begin{array}{c}\text { GOLD C } \\
\%\end{array}$ & $\begin{array}{c}\text { GOLD 4 } \\
\%\end{array}$ & $\begin{array}{c}\text { GOLD D } \\
\%\end{array}$ \\
\hline LAMA, LABA, u-LABA & 13.34 & 42.85 & 14.28 & 6.67 & 33.34 & 8.69 \\
\hline LABA + ICS & 53.34 & 28.57 & 85.71 & 60.00 & 22.23 & $* 91.3$ \\
\hline TEOF & 93.34 & 85.71 & 100.00 & $* 46.67$ & 77.78 & 73.91 \\
\hline SABA and/or SAMA & 86.67 & 57.14 & 42.85 & 73.34 & 77.78 & 60.86 \\
\hline
\end{tabular}

Legend: LAMA = long acting muscarinic antagonists;LABA = long-acting beta agonists u-LABA = ultra-long-acting beta agonists; ICS = inhaled corticosteroids;

TEOF $=$ Theophylline; SABA = short-acting beta agonists; SAMA = short-acting muscarinic antagonist

In the group GOLD 2 were treated with inhaled corticosteroids 53.34\% of patients and group GOLD B 28.57\% of patients. This practice is not in accordance with the recommendations GOLD 2011 neither GOLD 2006 (1, 11).

The significant decrease prescribing of theophylline was in the group GOLD C. The nonsignificant decrease was in groups GOLD B and GOLD D. This trend is consistent with the recommendations of GOLD. The current guidelines regard theophylline as less effective and less well tolerated even in comparison with long-acting bronchodilators. The therapeutic value of this drug should be reconsidered and investigated in further studies (8).

\section{Exacerbations}

The assessment of the number and severity of exacerbations is a very important parameter for evaluating the success of the therapy and progress of the disease. The increasing number of exacerbations of COPD was directly proportional with increasing stage of disease in all groups. In the group 2008 were 35 patients with 41 exacerbations and in the group 2013 were 49 patients with 64 exacerbations, which lead to hospitalization.

In the group 2008 the average number of exacerbations per year was for GOLD 2 - 1.06 (SD \pm 0.25$)$; GOLD $3-1.37$ (SD \pm 0.51$)$ and GOLD $4-1.45$ (SD \pm 0.72$)$. In the group 2013 it was for GOLD B - 1.0 (SD \pm 0 ); GOLD C - 1.25 (SD \pm 0.44 ) and GOLD D - 1.42 (SD \pm 0.85 ). The comparison of groups in 2008 and 2013 shows that the patients treated according to the principles of guidelines GOLD 2011 had on average, less exacerbations leading to hospitalization, in all stages of the disease. However, this difference is not significant.

\section{Comorbidities}

The associated diseases in patients with COPD can be independent of the severity of the spirometry results (9). Their presence and progression worsen quality of life, increase the number of hospital admissions and mortality. The new guidelines GOLD recommend 
consistent treatment of comorbidities, as well as their proactive detection. In our study was evaluated presence most common comorbidities, which were cardiovascular diseases (arterial hypertension, ischemic heart disease, arrhythmias, heart failure, myocardial infarction), dyslipidemia, diabetes mellitus, chronic renal insufficiency, gastroduodenal ulcer disease, osteoporosis, malignancies of the lungs and stomach. The occurrence of the comorbidities is in Fig. 3.

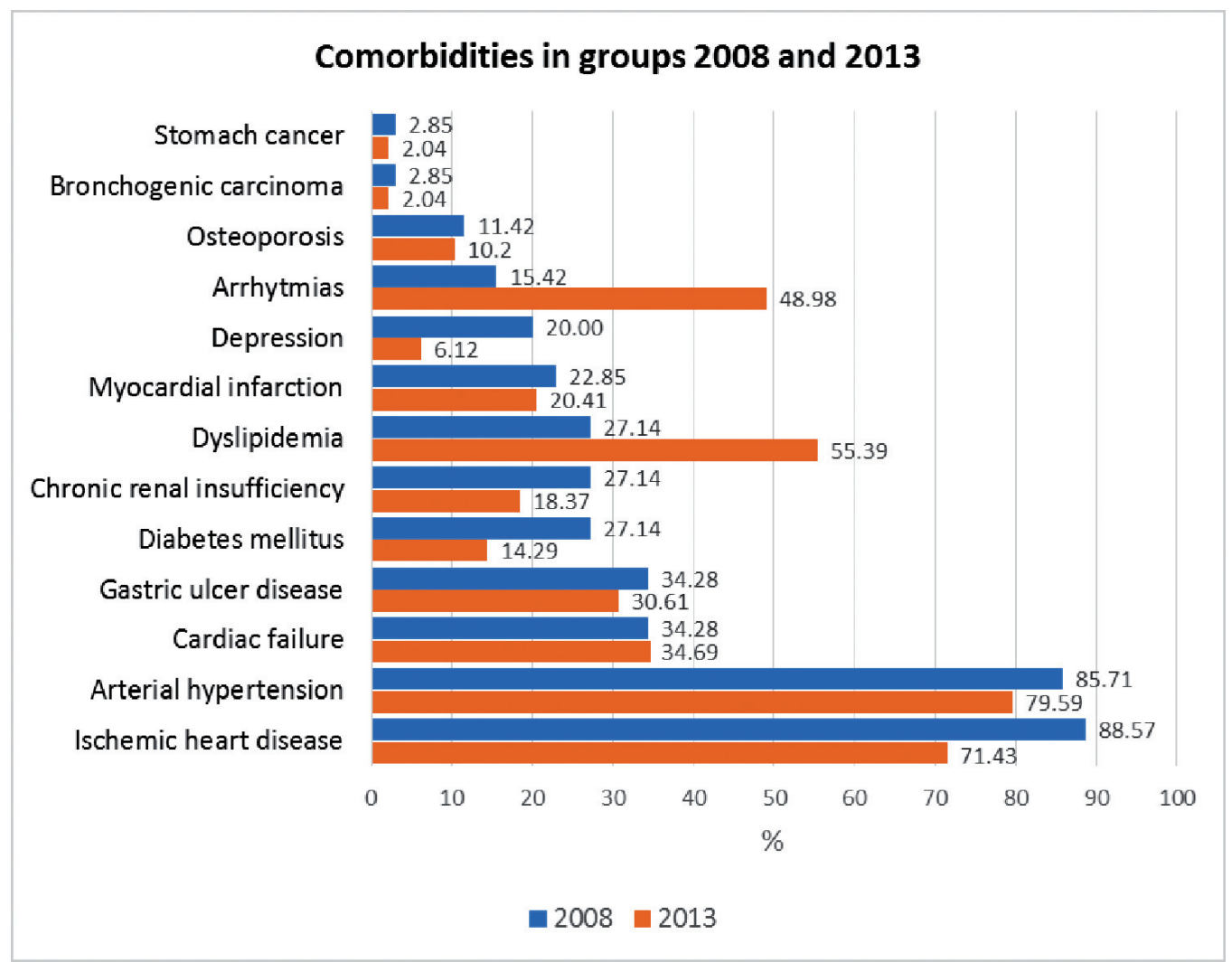

Fig 3. The occurrence of co-morbidities in groups 2008 and 2013, in percentage.

\section{Mortality till 1 year}

The mortality data were obtained after entering of identification number from the Healthcare Surveillance Authority (10). In group 2008 within one year died 16 patients, it was $54.71 \%$ of the group, of which 7 patients died directly during a hospitalization for disease exacerbation. From the group of dead patients were 14 men and 2 women.

In the group 2013 within one year died 15 patients, which was $44.11 \%$ the total number of group. During the hospitalization for disease exacerbation died 6 patients. From all 15 died patients within one year 12 men and 3 women.

Based on our results it is possible conclude that in group 2013 the survival rate was higher in all stages of the disease and the average age at death was higher in groups GOLD $\mathrm{B}$ and GOLD $\mathrm{C}$ This difference was not statistically significant. Comparison of the results illustrates in the percentage Fig 4. 


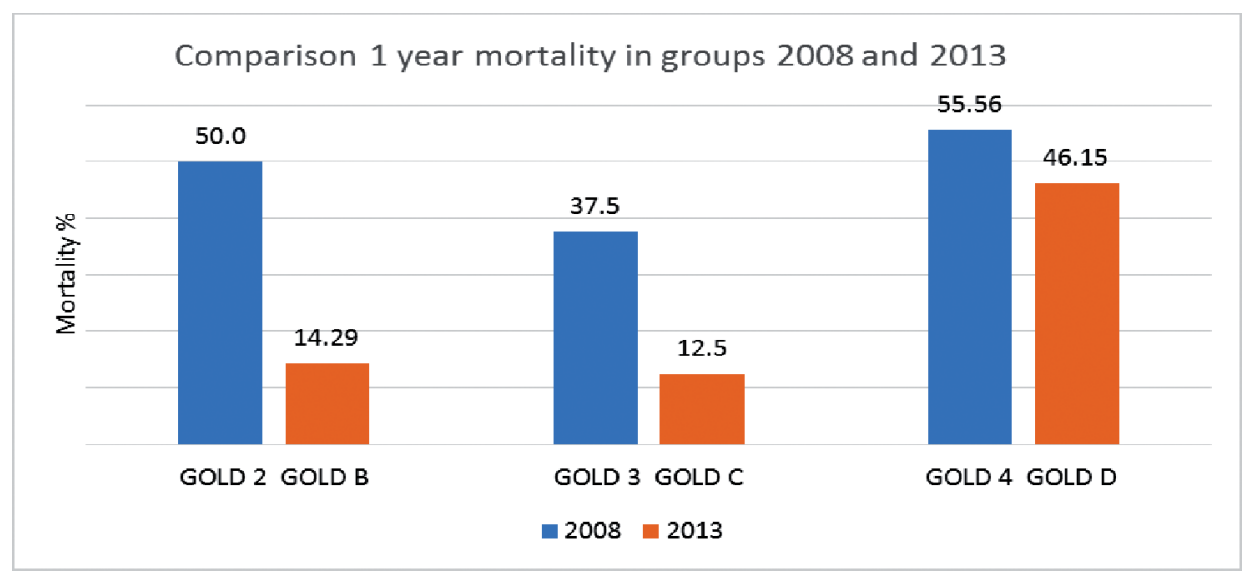

Fig. 4 Mortality till 1 year, in relation to the stage of the disease in groups 2008 and 2013

\section{DISCUSSION}

Slovakia recorded important progress of implementation of clinical recommended practices into routine practice in recent years. The adherence of recommendation is dependent on the consent and acceptance of new recommendations, on the willingness to accept a procedure, on the availability of recommendations (language availability, information availability, economic availability) and not least on the expected results (3).

We have recorded improving implementation of the recommended clinical practice guidelines. In the whole group of 84 patients with exacerbation of COPD, were $75 \%$ males and 25\% females. This distribution correlates with other studies as SEVERCA (1) or CERTIMA (12). After finding of significant differences in spirometry between the groups GOLD 2 and GOLD B it is necessary to take note, that there was lower average age of patients in group GOLD B. At the same time it is necessary to consider the fact that spirometry performed during exacerbation of the disease is imprecise and a recovery after an exacerbation can lead to an improvement in spirometric parameters so that some patients can be reclassified on one stage. This was also confirmed in the vstudy by Rea et al. (8), who investigated the change in the spirometric parameters of the patients during hospitalization for an exacerbation and one month after discharge. The evaluation of treatment strategy results lead to conclusion, that there is still overuse of inhaled corticosteroids (ICS) in groups in which are not recommended. Our results show that in comparison with previous years there is a reduction in the number of patients with the "overtreatment" phenomenon. This result correlates with the SEVERCA study (1). The comparison of most frequently observed comorbidities showed a small unsignificant decrease in group 2013. It is necessary to take note that there was lower average age of patients in groups 2013. The results of this study are consistent with the work of Benčová et al. (9), wherein the authors identified the most common co-morbidities as cardiovascular diseases (ischemic heart disease, atrial fibrillation, heart failure, and arterial hypertension).

Patients with frequent exacerbations have in addition to health problem also a serious economic problem. The cost of treatment patients with exacerbation of COPD are more than double of the cost of treating patients without exacerbations $(6,2)$. More expensive treatment is in all stages of COPD patients with exacerbation in hospitalized patients as well as outpatient. Comparison of stages in 2008 and 2013 groups showed that patients treated according to the principles GOLD 2011 (group 2013) had on average fewer exacerbations leading to hospitalization in all stages of the disease. Evaluation of one-year mortality 
showed that the patients in group 2013 had higher survival percentages at all stages of the disease and a higher mean age at death. However, these results may be affected by errors caused by the small number of subjects in the various stages of the disease.

\section{CONCLUSIONS}

The results of our study show that there is an improvement in implementation of guidelines for diagnostic and treatment of COPD and thereby improving quality of healthcare. Despite the relatively small number of patients in our study it can be concluded that the careful implementation of recommended practices GOLD 2011 contributes to the efficient prevention, diagnosis, adequate treatment, increasing the quality and lengthening the life of patients with COPD. Except these facts, the application of the principles GOLD 2011 has significant economic effect. Despite the fact that it is a challenging and complex process of implementation of new recommended practices, it contributes to ensuring the overall homogeneity of provided healthcare.

\section{REFERENCES}

1. Solovic I, Lassan S, Smolkova K. SEVERCA- nové vyhodnotenie závažnosti CHOCHP. In: Respiro. 2014, roč. 12, č. 2 , s. 70 - 79. ISSN 1335-3985.

2. Rozborilova E.Manažment chronickej obštrukčnej choroby plúc z ekonomickej stránky. In: Respiro. 2014, roč. 12 , č. 2 , s. 60 - 69. ISSN 1335-3985.

3. Global Strategy for the Diagnosis, Management and Prevention of COPD, Global Initiative for Chronic Obstructive Lung Disease (GOLD) 2011. Available from: http://www.goldcopd.org/.

4. Global Strategy for the Diagnosis, Management and Prevention of COPD, Global Initiative for Chronic Obstructive Lung Disease (GOLD) 2013. Available from: http://www.goldcopd.org/.

5. Global Strategy for the Diagnosis, Management and Prevention of COPD, Global Initiative for Chronic Obstructive Lung Disease (GOLD) 2015. Available from: http://www.goldcopd.org/.

6. Kasak V. Chronická bostrukční plicní nemoc z pohledu farmakoekonomiky. In: Studia pneumologica et phthiseologica. 2012, roč. 72, č. 2, s. 54 - 62. ISSN 1213-810X.

7. Salinas, Gregory D. et al. Barriers to adherence to chronic obstructive pulmonary disease guidelines by primary care physicians. In: International Journal of Chronic Obstructive Pulmonary Disease. 2011, roč. 6, s. 171 - 179.

8. Rea H, Kenealy T, Adair J. Spirometry for patients in hospital and one month after admission with an acute exacerbation of COPD. In: International Journal of Chronic Obstructive Pulmonary Disease. 2011; č.6, s. 527-532.

9. Bencova A. et al. Komorbidity a chronická obštrukčná choroba plúc. In: Studia pneumologica et phthiseologica. 2014 , roč. 74 , č. $2 / 2014$, s. $65-73$.

10. Global Strategy for the Diagnosis, Management and Prevention of COPD, Global Initiative for Chronic Obstructive Lung Disease (GOLD) 2015. Available from: http://www.goldcopd.org/

11. https://www.portaludzs.sk/web/eportal/

12. Kos, S, Weber M. Národní klinický registr CERTIMA segment CHOPN- výsledky 2. roku sledování nemocných. Studia pneumologica et phthiseologica. 2014, roč. 74 , č. 2 , s. $62-64$.

13. De Coster, Daan A., Jones M. Tailoring of corticosteroids in COPD management. Current Respiratory Care Reports [online]. 2014, 3 (3): $121-132$.

14. Fexer J, et al. The Effects of Theophylline on Hospital Admissions and Exacerbations in COPD Patients. Deutsches Ärzteblatt International 2014, 111 (17): 293 - 300.

15. Soriano JB. et al. Distribution and prognostic validity of the new global initiative for chronic obstructive lung disease grading classification. Chest 2013, 143 (3): $694-702$.

16. Soriano JB, Zielinski J, Price D. Screening for and early detection of chronic obstructive pulmonary disease. The Lancet 374, č. 9691. [cit. 13.10.2013], s. 721 - 732. ISSN 0140-6736. 